Faculty of Science

Faculty Publications

This is a post-review version of the following article:

Dynamic electrochemical impedance study of methanol oxidation at Pt at elevated temperatures

Thomas Holm, Per Kristian Dahlstrøm, Svein Sunde, Frode Seland, David A. Harrington

February 2019

The final published version of this article can be found at:

http://dx.doi.org/10.1016/j.electacta.2018.10.071

Citation for this paper:

Holm, T., Dahlstrøm, R.K., Sunde, S., Seland, F. \& Harrington, D.A. (2019).

Dynamic electrochemical impedance study of methanol oxidation at Pt at elevated temperatures. Electrochimica Acta, 295, 139-147.

https://doi.org/10.1016/j.electacta.2018.10.071 
(C) 2018. This manuscript version is made available under the CC-BY-NC-ND 4.0 license

http://creativecommons.org/licences/by-nc-nd/4.0/

\title{
Dynamic electrochemical impedance study of methanol oxidation at Pt at elevated temperatures
}

\author{
Thomas Holm ${ }^{\mathrm{a}, * *}$, Per Kristian Dahlstrøm ${ }^{\mathrm{a}, \mathrm{b}}$, Svein Sunde ${ }^{\mathrm{b}}$, Frode Seland ${ }^{\mathrm{b}}$, David A. Harrington ${ }^{\mathrm{a}, *}$ \\ ${ }^{a}$ Department of Chemistry, University of Victoria, Victoria, British Columbia, V8W 3V6, Canada. \\ ${ }^{b}$ Department of Materials Science and Engineering, Norwegian University of Science and Technology (NTNU), NO-7491 Trondheim, \\ Norway.
}

\begin{abstract}
The methanol oxidation reaction (MOR) is studied at temperatures up to $140^{\circ} \mathrm{C}$ by a combination of cyclic voltammetry, chronoamperometry, and dynamic electrochemical impedance spectroscopy (dEIS). A mechanistic analysis of the reaction is done based on the Tafel relation, the calculated activation energy, and the fitting of dEIS data. At the fuel cell relevant potentials, $0-0.80 \mathrm{~V}$ vs RHE, the MOR mechanism is similar at all temperatures. The rate-determining steps is the adsorption of water at low overpotentials $(<0.50 \mathrm{~V}$ vs RHE), a combination of the methanol adsorption reaction and the surface reaction between adsorbed $\mathrm{CO}$ and $\mathrm{OH}$ at intermediate potentials $(0.50-0.65 \mathrm{~V}$ vs RHE), and the methanol adsorption reaction at high potentials $(>0.65 \mathrm{~V}$ vs RHE). The shoulder on the oxidation peak at $0.60-0.65$ $\mathrm{V}$ vs RHE corresponds well with where the CO coverage approaches zero.
\end{abstract}

Keywords:

Electrochemical Impedance Spectroscopy, Methanol Oxidation, Temperature, Reaction Mechanism

\section{Introduction}

The methanol oxidation reaction (MOR) attracts interest due to its application in direct methanol fuel cells (DMFCs) [1-4]. Platinum is the best mono-metallic catalyst for the MOR and on $\mathrm{Pt}$ in acidic solution, the MOR proceeds through a dual pathway mechanism [5]. The pathways are commonly denoted as the indirect pathway, through strongly adsorbed $\mathrm{CO}$ and further oxidation to $\mathrm{CO}_{2}$, and the direct pathway, through short-lived or no adsorbates yielding formaldehyde, formic acid, or $\mathrm{CO}_{2}$. A high selectivity towards $\mathrm{CO}_{2}$ production is desirable due to both higher efficiency and because formaldehyde and formic acid are toxic products. An increase in reaction temperature gives higher selectivity towards $\mathrm{CO}_{2}$ produc-

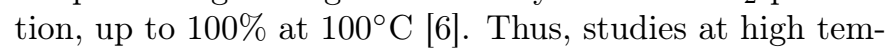
perature can help in understanding the MOR at high $\mathrm{CO}_{2}$ yield and high overall reaction rate.

A simplified reaction mechanism for the indirect pathway is given in Eqs. (1)-(3) [7, 8]. From this mechanism, it is evident that the adsorbates, $\mathrm{PtCO}$ and $\mathrm{PtOH}$ (from now called "CO" and "OH"), play a major role in the reaction. $\mathrm{CO}$ is known to be present at high coverages at low

\footnotetext{
${ }^{*}$ Corresponding author. Tel.: +1-250-721-7166

** Current address: Clean Energy Research Centre (CERC), University of British Columbia, Vancouver, British Columbia, V6T 1Z4, Canada.

Email addresses: thomas.holm@ubc.ca (Thomas Holm), perkrid@equinor.no (Per Kristian Dahlstrøm), svein.sunde@ntnu.no (Svein Sunde), frode.seland@ntnu.no (Frode Seland), dharr@uvic.ca (David A. Harrington)
}

potentials and may block the MOR [9-11]. The activation of water, Eq. (2), also has a large effect. This is well illustrated by the success of bimetallic catalysts where $\mathrm{Pt}$ is combined with a co-catalyst with higher affinity towards water, e.g., $\mathrm{Ru}, \mathrm{Sn}, \mathrm{Cu}[12]$. It should be noted that the nature of the adsorbed water is not entirely clear, and it can be either $\mathrm{OH}, \mathrm{O}$, or some form of activated water [13]. The $\mathrm{pH}$ also has a large effect on the reaction rates [14], and might influence the nature of these species and the overall reaction mechanism. Conventional electrochemical methods like cyclic voltammetry and chronoamperometry are commonly used to examine reaction kinetics. However, these methods are often inconclusive when studying multistep reactions involving several adsorbates, e.g., the MOR $[15,16]$. Therefore, complementary techniques are necessary to distinguish closely-related mechanisms.

$$
\begin{gathered}
\mathrm{Pt}+\mathrm{CH}_{3} \mathrm{OH} \rightarrow \mathrm{PtCO}+4 \mathrm{H}^{+}+4 \mathrm{e}^{-} \\
\mathrm{Pt}+\mathrm{H}_{2} \mathrm{O} \leftrightarrows \mathrm{PtOH}+\mathrm{H}^{+}+\mathrm{e}^{-} \\
\mathrm{PtCO}+\mathrm{PtOH} \rightarrow \mathrm{CO}_{2}+2 \mathrm{Pt}+\mathrm{H}^{+}+\mathrm{e}^{-}
\end{gathered}
$$

Electrochemical impedance spectroscopy (EIS) has great potential as a tool in mechanistic studies [17-22]. In particular, EIS run over a wide frequency range can help identify processes with different time constants. EIS also has the advantage that it can be run simultaneously with cyclic voltammetry as dynamic EIS (dEIS). For the MOR, EIS and dEIS have been used for mechanistic analysis [23-33]. In particular, work by Sundmacher and coworkers [16, 29] 
demonstrates the way that EIS can be used to provide essential information when elucidating reaction kinetics.

In this work, a recently developed apparatus for high temperature aqueous electrochemistry [34, 35] was used to study methanol oxidation between $21^{\circ} \mathrm{C}$ and $140^{\circ} \mathrm{C}$. The heating program was optimized from the earlier work to make it possible to run slow experimental techniques, i.e., low sweep rate $\left(\leq 5 \mathrm{mV} \mathrm{s}^{-1}\right)$ cyclic voltammetry, chronoamperometry, and dEIS. A mechanistic analysis of data from all three types of experiments is used to suggest a five-step reaction mechanism for the indirect pathway.

\section{Experimental}

A commercially available autoclave (BüchiGlasUster AG) was custom fitted for electrochemical experiments as described in previous work [34, 35]. The working and counter electrodes were platinum wires sealed in glass (a geometric area of $0.01 \mathrm{~cm}^{2}$ for the working electrode and $0.08 \mathrm{~cm}^{2}$ for the counter electrode), and the reference electrode was a reversible hydrogen electrode (RHE) in the same electrolyte at the same temperature. All potentials are reported vs this reference electrode. Temperatures were calibrated by running a slow controlled heating program with inert electrolyte (water) according to the procedure described in previous work [34], and have an estimated error of $\pm 3 \mathrm{~K}$. The solutions used were all made from ultrapure water (Millipore Milli-Q $18 \mathrm{M} \Omega \mathrm{cm}$ ), sulfuric acid (SeaStar Baseline) and methanol (Alfa Aesar, electronic grade $>99.9 \%$ ). The experiments were conducted in $0.5 \mathrm{M}$ sulfuric acid with and without $1 \mathrm{M}$ methanol. Total electrolyte volume was fixed at $200 \mathrm{~mL}$ in all experiments.

A Gamry Ref 600 potentiostat was used for all experiments. Before methanol was added to the solution, the electrochemically active surface area of the working electrode was calculated from the integration of hydrogen adsorption peaks during cyclic voltammograms at $100 \mathrm{mV}$ $\mathrm{s}^{-1}$ at room temperature between 70 and $300 \mathrm{mV}$. The electrochemically active surface area (ECSA) of the working electrode was determined from the hydrogen adsorption peak assuming a charge of $220 \mu \mathrm{C}$ for one monolayer of hydrogen. The ECSA was assumed to be independent of temperature and was $0.015 \mathrm{~cm}^{2}$.

The temperatures used were $21^{\circ} \mathrm{C}$ (room temperature), $40^{\circ} \mathrm{C}, 60^{\circ} \mathrm{C}, 80^{\circ} \mathrm{C}, 100^{\circ} \mathrm{C}, 120^{\circ} \mathrm{C}$, and $140^{\circ} \mathrm{C}$. Cyclic voltammetry $\left(200 \mathrm{mV} \mathrm{s}^{-1}\right)$ was performed during heating to monitor the temperature change, and a temperature change was deemed complete when 20 full cycles overlapped. At each temperature, a series of cyclic voltammograms with sweep rates between 5 and $1000 \mathrm{mV} \mathrm{s}^{-1}$ were recorded. Steady-state experiments were performed by (1) running cyclic voltammetry for 5 cycles at $200 \mathrm{mV} \mathrm{s}^{-1},(2)$ holding the potential at $0.1 \mathrm{~V}$ for $60 \mathrm{~s},(2 \mathrm{a})$ stepping to $1.0 \mathrm{~V}$ for $1 \mathrm{~s}$ (henceforth called the pre-step) and (3) stepping to the given potential for $100 \mathrm{~s}$ (between 0.20 and $0.60 \mathrm{~V}$ vs
RHE). All measurements were performed with and without the "pre-step" (step 2a). Potentiostatic EIS was run at each temperature at $0.5 \mathrm{~V}, 0.8 \mathrm{~V}$, and $1.2 \mathrm{~V}$ to measure the solution resistance and ensure that it has minimal influence on the measurements.

Dynamic EIS (dEIS) was run by using custom software as described in previous publications $[21,36]$. Impedance was measured with a minimum frequency of $1 \mathrm{~Hz}$, maximum frequency of $13 \mathrm{kHz}$, and a maximum total amplitude of $30 \mathrm{mV}$. The selected frequencies were chosen using the system described by Popkirov [37], and the signal amplitude was halved for every decade increase in frequency. dEIS was run at two sweep rates, $5 \mathrm{mV} \mathrm{s}^{-1}$ and $20 \mathrm{mV}$ $\mathrm{s}^{-1}$, at all temperatures measured. The post-processing allows for impedance spectra to be calculated at any potential during the continuous sweep, using data over $1 \mathrm{~s}$ centered at that potential.

The dEIS impedance spectra were interpreted by fitting to equivalent circuits using ZView software (v. 3.5a, Scribner Associates Inc). The fitting method in the ZView software may yield poor results if the initial values are far from optimum. Therefore, a series of up to 8 sets of initial values was used to find the global best fit for a given equivalent circuit. In all cases, the solution resistance was found from the high-frequency intercept in the steady-state impedance measurements and kept constant during fitting of dEIS spectra. All the measured spectra were fitted using the 6 different equivalent circuits shown in Fig. 1, but based on the visual interpretation (Fig. 5), the valid circuits for a given potential zone were limited to two or three equivalent circuits. The different zones are discussed in detail in Section 3.4.

A fitted circuit was considered valid if all the following criteria were met:

i) The error for any parameter was less than $200 \%$. In the potential regions where the parameters fall on a common line, the errors for the kinetic parameters $R_{1}, R_{\mathrm{ct}}$ and $L_{1}$ were typically below $25 \%$ but to also know what is happening in the transitions zones (where the impedance spectra changed character over small potential range) the larger global error criterion of $200 \%$ was chosen.

ii) For CPE parameters, the $\alpha$ value (from $Z_{\mathrm{CPE}}=$ $\left.1 /(j \omega)^{\alpha} Q\right)$ had a value between 0.65 and 1.0 .

iii) The F-test was valid at the $99 \%$ confidence level, i.e., there must be statistically less than $1 \%$ chance that the added circuit element(s) gave a better fit by chance. This was determined by using Eq. (4) and the scipy.stats.f.cdf command in python. In Eq. (4), $a$ is the difference in the number of parameters between the two circuits, $\chi^{2}$ is the fit quality, $n$ is the number of circuit elements in the new circuit, and $N$ is the number of fitted frequencies (= $=46$ in this work).

$$
F(a, 2 N-n)=\frac{\left(\chi^{2}(n-a)-\chi^{2}(n)\right) / a}{\chi^{2}(n) /(2 N-n)}
$$

Any spectra that did not fulfill all the criteria i)-iii) for 
$1 \tau$
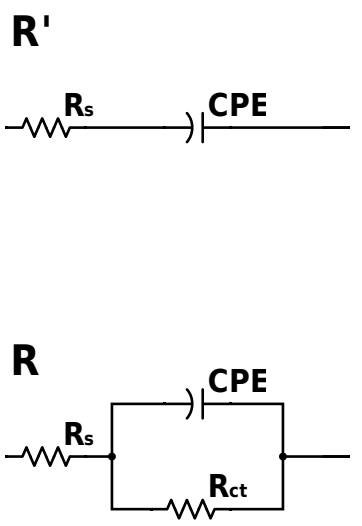

$2 \tau$
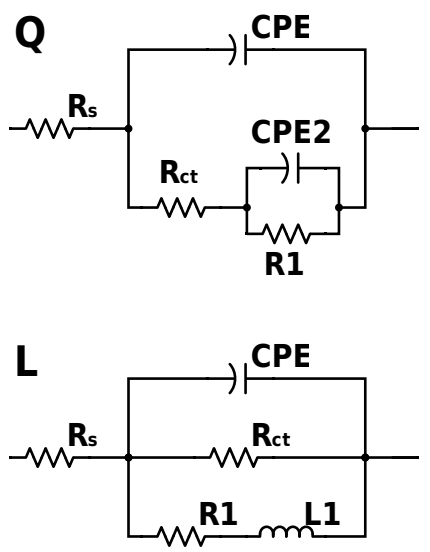

$3 \tau$
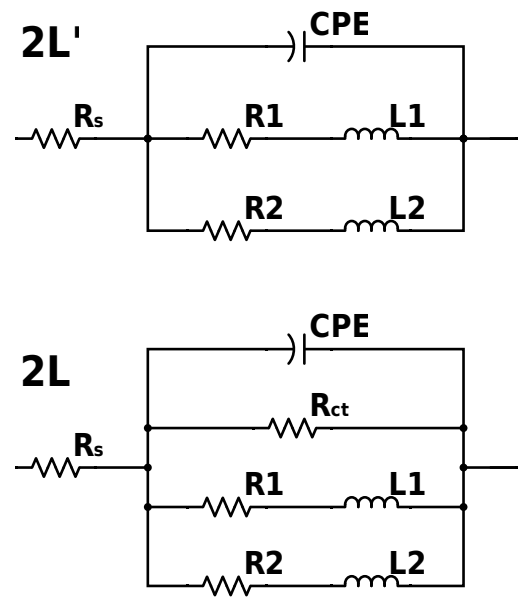

Figure 1: Equivalent circuits used in this work sorted by the number of time constants.

any of the circuits in Fig. 1 was not used in the subsequent analysis.

\section{Results and discussion}

\subsection{Preface}

The following literature observations form the foundation for all discussion on the mechanism of methanol oxidation on platinum:

(1) Methanol oxidation at potentials below $0.5 \mathrm{~V}$ leads to adsorbed $\mathrm{CO}$ at the surface. This is assumed to be the dominant adsorbed reaction intermediate [38, 39].

(2) Multiple Pt sites are necessary for methanol adsorption and dehydrogenation to CO [12, 40, 41].

(3) CO saturation coverage is at a maximum at about $0.55 \mathrm{~V}$ and decreases with increasing potential [9-11].

(4) Dissociative water adsorption is reversible and not considered a possible rate-determining step. When this reaction does not occur, the adsorbed $\mathrm{CO}$ cannot oxidize to $\mathrm{CO}_{2}[42,43]$.

(5) Formation of platinum oxide at high potentials reduces the methanol oxidation rate drastically and is the main reason for the current maximum at about $0.8 \mathrm{~V}$.

These observations lead to the partial conclusion that the indirect pathway has two possible rate-determining steps, CO production through dissociative methanol adsorption (Eq. (1)) or CO oxidation to $\mathrm{CO}_{2}$ (Eq. (3)). The direct pathway plays a lesser role, and it is not treated in detail here. The absence of significant coverages of adsorbed species other than CO was long accepted, which would lead to the conclusion that methanol adsorption is rate-determining in the direct pathway. More recently, Chen et al. showed that formate was present on the surface and assigned this to be the dominating intermediate in the direct pathway [9]. However, the role of formate in the direct pathway has been questioned [44]. The reader is referred to a recent work by Chen and coworkers for an example of an experimental setup that can distinguish between products, including $\mathrm{CO}_{2}$, produced through the different reaction pathways [45]. In any case, the present methods do not prove sensitive to the direct pathway so we do not deal with it explicitly.

\subsection{Cyclic voltammetry}

The positive-going part of cyclic voltammograms recorded at $5 \mathrm{mV} \mathrm{s}^{-1}$ of methanol oxidation on platinum are shown in Fig. 2 represented as (a) current vs potential plots, (b) close-up at the onset of high-rate methanol oxidation, and (c) the logarithm of the current density vs potential. The temperature increase has a large effect on the peak current density, giving approximately 400 times higher current at $140^{\circ} \mathrm{C}$ compared to $21^{\circ} \mathrm{C}$. The temperature change also influences the onset of methanol oxidation giving a clear negative shift in the onset potential from about $0.6 \mathrm{~V}$ at $21^{\circ} \mathrm{C}$ to about $0.4 \mathrm{~V}$ at $140^{\circ} \mathrm{C}$. In the plot of the logarithmic current, Fig. 2c, the increase in temperature seems to have a similar effect at all temperatures, with an increase in the overall rate and similar trend. Notably, at lower temperatures $\left(<80^{\circ} \mathrm{C}\right)$, a shoulder peak is visible at about $0.60-0.65 \mathrm{~V}$. At higher temperatures $\left(>80^{\circ} \mathrm{C}\right)$, only a slight change in the slope is visible at approximately the same potentials. The peak potential corresponds to the onset of platinum oxidation and subsequently leads to deactivation of the platinum surface towards methanol oxidation, resulting in a decrease in current as the potential is increased [35]. After the platinum oxide has been formed, the current density remains low until (i) oxygen evolution occurs (at potentials above $1.5 \mathrm{~V}$ ), or (ii) the 

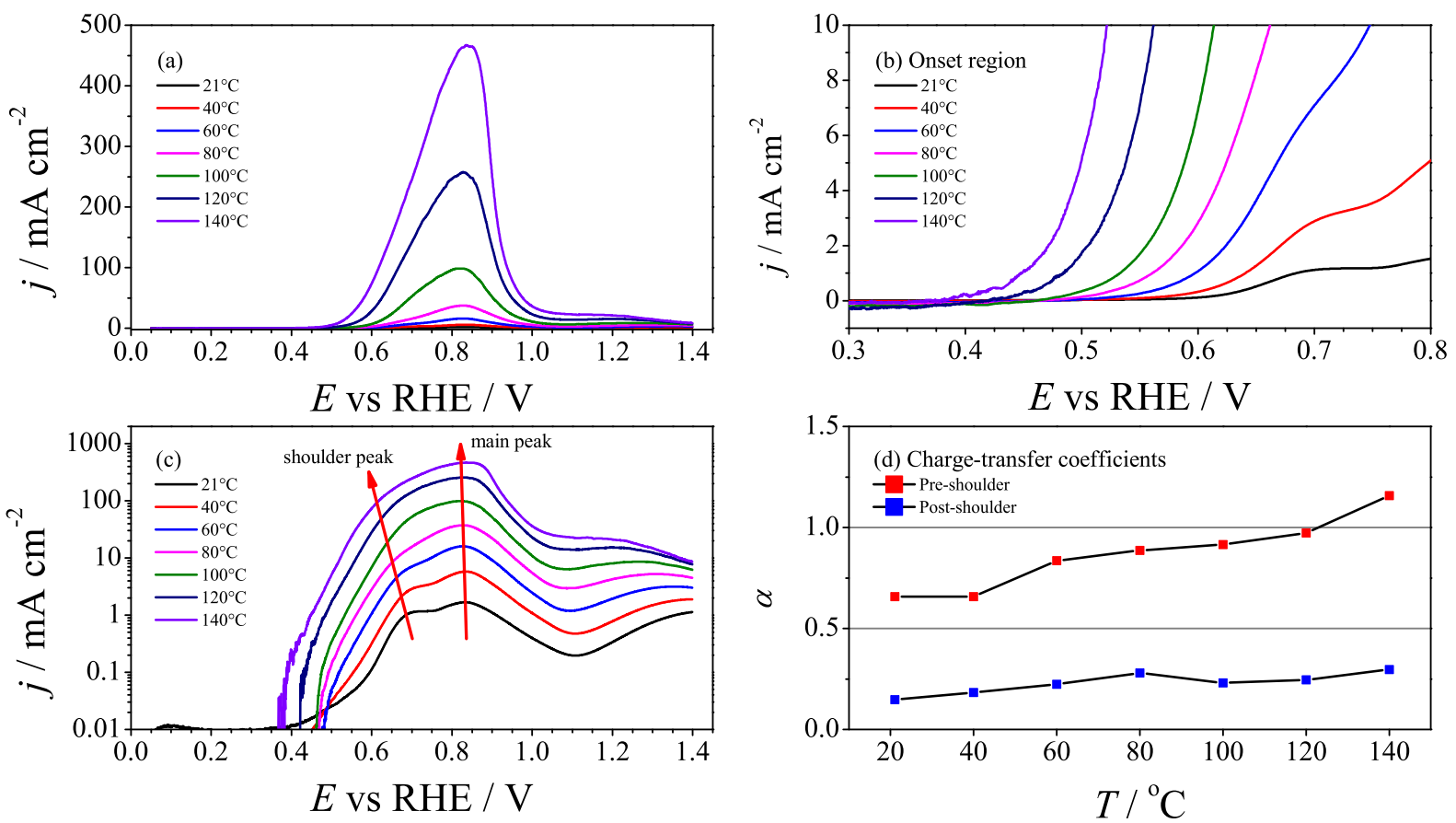

Figure 2: Figure cyclic voltammetry data recorded at $5 \mathrm{mV} \mathrm{s}^{-1}$ at temperatures between $21^{\circ} \mathrm{C}$ and $140^{\circ} \mathrm{C}$. The data is presented as (a) standard current density vs potential, (b) close-up of onset potentials of methanol oxidation, (c) the logarithm of the current density vs potential, and (d) calculated charge-transfer coefficients from the experimental Tafel slopes.

platinum oxide is reduced during the reverse sweep (not shown here).

In the fuel cell relevant range between 0 and $0.8 \mathrm{~V}$, three different linear zones can be seen in Fig. 2c, (i) an initial slope until the onset of $\mathrm{CO}$ oxidation (only visible for $21^{\circ} \mathrm{C}$ at $E<0.5 \mathrm{~V}$ ), (ii) from the onset of $\mathrm{CO}$ oxidation until the shoulder peak, and (iii) from the shoulder peak until the main peak. The first slope is visible at potentials lower than the potential where water is activated on platinum [42, 46-48] indicating that the source of this slope is the CO production step, Eq. (1). This is also supported by the observed increase in CO coverage by FTIR as a function of potential in this region $[9,11]$. At higher temperatures, this slope is likely masked by the reduction of small amounts of dissolved $\mathrm{O}_{2}$ leading to a net cathodic current at these potentials.

The Tafel equation $\left(j=j_{0} \exp (\alpha F E / R T)\right)$ was fitted to the linear zones before and after the shoulder peak, and the charge-transfer coefficients, $\alpha$, from the fitted slopes are shown in Fig. 2d. Under the usual assumptions, the interpretation of such data can be summarized by Eq. (5) [49].

$$
\alpha=m+n(1-\beta)
$$

Here, $\beta$ is the symmetry coefficient from the rate-determin step (from Red $\rightarrow \mathrm{Ox}+n e^{-}, j_{\mathrm{rds}}=n F k_{0} \exp (n(1-$ $\beta) F \eta / R T), m$ is the number of electrochemical steps preceding the rate-determining step, and $n$ is the number of electrons in the rate-determining step (assumed to be 0 or 1). Assuming a symmetry coefficients, $\beta$, of 0.5 , a set of simple rules can be found: (i) $\alpha=0$ indicates a chemical rate-determining step before any electron-transfer steps ( $m=0, n=0$ ), (ii) $\alpha=0.5$ indicates that the first electron-transfer is rate determining $(m=0, n=1)$, (iii) $\alpha=1$ indicates a chemical rate-determining step preceded by an electrochemical step $(m=1, n=0)$, and (iv) $\alpha=1.5$ indicates an electrochemical rate-determining step preceded by an electrochemical step $(m=1, n=1)$.

Before the shoulder peak, the charge-transfer coefficients have values of about 0.66 at $21^{\circ} \mathrm{C}$, and this slowly increases as the temperature increases to a value of 1.21 at $140^{\circ} \mathrm{C}$. The reported values indicate that the reaction mechanism is changing as the temperature increases and are in the ranges previously reported in the literature [50]. A reaction step preceded by at least one electrochemical step, such as the surface reaction between the adsorbates, Eq. (3), is a potential rate-determining step. Notably, the potential range having this slope, $0.40-0.60 \mathrm{~V}$, is where the CO coverage is changing rapidly $[9,11]$, at least at room temperature. The fast change and high amount of $\mathrm{CO}$ coverage makes any conclusion based on this simplistic Tafel analysis dubious. Likely, the change as a function of temperature indicates that the overall reaction mechanism is controlled by more than one reaction step.

After the shoulder peak, the Tafel slope changes (Fig. ${ }_{2 \mathrm{c}}$ ) resulting in a charge-transfer coefficient between 0.15 and 0.30 for the temperature range reported. The postshoulder slopes are similar to the slope at $E<0.5 \mathrm{~V}$ at $21^{\circ} \mathrm{C}$ and slopes previously reported in the literature [39, 51-53]. Therefore, we follow the literature and attribute 

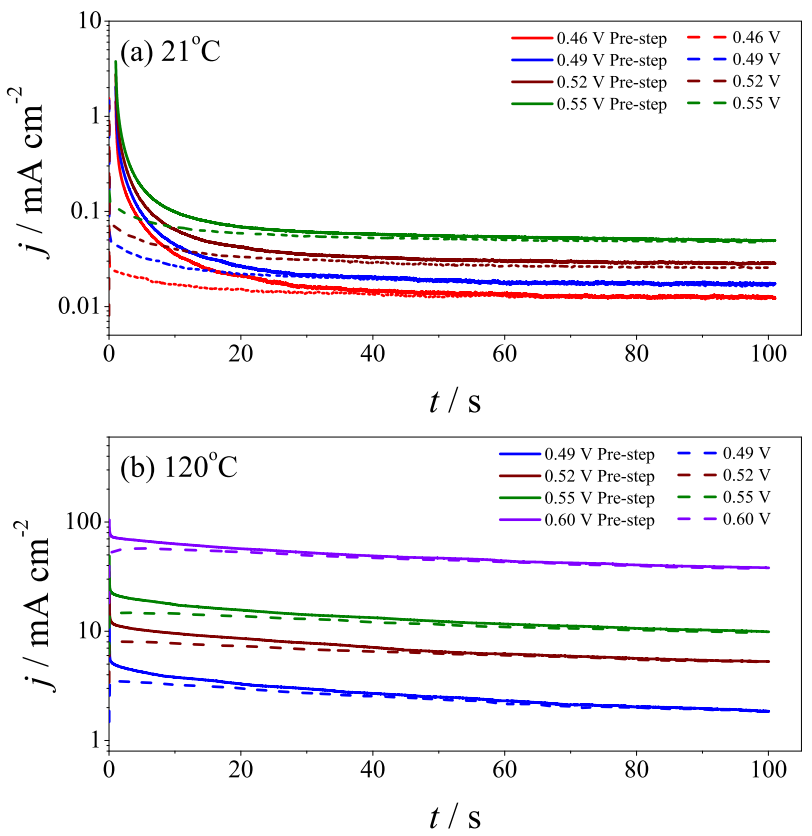

Figure 3: Chronoamperometry measured at $21^{\circ} \mathrm{C}$ (a) and at $120^{\circ} \mathrm{C}$ (b) for results with (full line) and without (stipled line) voltage step at $1.0 \mathrm{~V}$ vs RHE.

this to the methanol dissociative adsorption step, Eq. (1). This is further supported by the low CO coverage reported at these potentials through ATR-FTIR [7, 11, 54] meaning that any $\mathrm{CO}$ produced quickly reacts to $\mathrm{CO}_{2}$ through Eq. (3). In addition, calculations from first principles support a symmetry coefficient, $\beta$, for methanol adsorption above 0.5 (resulting in $\alpha<0.5)[55,56]$. However, it is often found that real symmetry coefficients can have values far from the commonly assumed 0.5 [57].

\subsection{Chronoamperometry}

To investigate the influence of the adsorbed $\mathrm{CO}$, a set of chronoamperometry experiments were designed to study the methanol oxidation reaction when the potential is stepped from a potential with high $\mathrm{CO}$ coverage and a potential with low CO coverage. Thus, the regular chronoamperometry was recorded by stepping from a potential where high $\mathrm{CO}$ coverage is expected, $0.1 \mathrm{~V}$. In the other case, the pre-step case, the potential was quickly stepped from $0.1 \mathrm{~V}$ to a high potential that strips $\mathrm{CO}$ from the surface [9], 1.0 V for $1 \mathrm{~s}$, and then to the desired potential. Representative experimental data are shown in Fig. 3 at (a) $21^{\circ} \mathrm{C}$ and (b) $120^{\circ} \mathrm{C}$. The pre-step influenced the reaction rate, especially at shorter times $(t<20 \mathrm{~s})$. However, the current at $100 \mathrm{~s}$ is largely independent of the prestep indicating that the same steady-state conditions are reached. Assuming that the current is a sum of a steadystate current and a transient current, the time constant of the transient current can be estimated as the time where the transient current is 1 /e times the initial value assuming no charging or mass-transport effects. At $21^{\circ} \mathrm{C}$, this
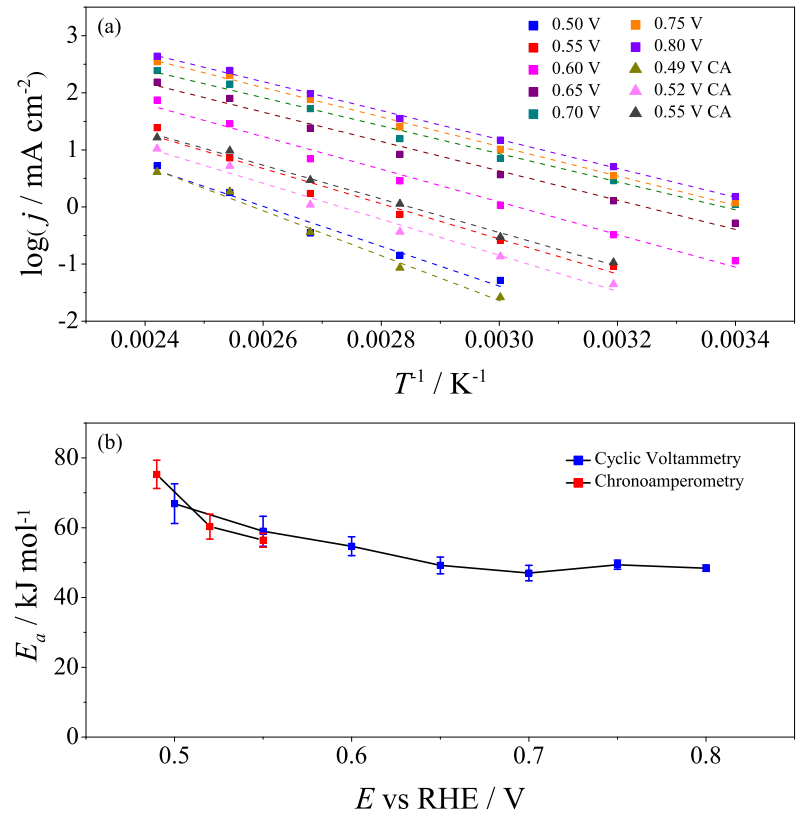

Figure 4: Figure showing (a) the logarithm of the current density vs the inverse temperature including the regression results (stipled lines), (b) the resulting activation energies with error bars of 1 standard deviation for data from chronoamperometry measurements (blue) and from cyclic voltammetry (red).

is about $2 \mathrm{~s}$, while at $120^{\circ} \mathrm{C}$ it is about $0.05 \mathrm{~s}$. Neglecting charging effects, the difference between the chronoamperometry experiments with and without the pre-step is the CO coverage. Thus, we conclude that the relaxation observed is due to the change in CO coverage from the initial stage value to a steady-state value.

\section{Activation energy}

The activation energies, $E_{\mathrm{a}}$, were calculated from both cyclic voltammetry (blue) at $5 \mathrm{mV} \mathrm{s}^{-1}$ and steady-state measurements after $100 \mathrm{~s}$ (red) and are presented in Fig. 4. It is evident that the two measurement methods give activation energies within one standard deviation of each other indicating that a sweep rate of $5 \mathrm{mV} \mathrm{s}^{-1}$ is close enough to steady-state conditions to yield similar results. The activation energy, $E_{\mathrm{a}}$, is in the range $50-80 \mathrm{~kJ} \mathrm{~mol}^{-1}$, and slowly decreases as the potential increases. This value is in accordance with previously published results [2, 13], and is attributed to dissociative adsorption steps [2]. Any such interpretation assumes that other parameters aside from temperature, such as CO coverages, are constant with temperature. At lower potentials $(<0.65 \mathrm{~V})$, the absolute $\mathrm{CO}$ coverage at a given potential would be expected to decrease with an increase in temperature, and this may constitute an additional catalytic effect giving a different activation energy value than a single reaction step would give. Thus, dissociative methanol adsorption, Eq. (1), is a good candidate for the rate-determining step at lower potentials, but the change in $\mathrm{CO}$ coverage also influence the rate. 
The results from cyclic voltammetry and chronoamperometry can be summarized by the three potential zones. At low potentials, $<0.50 \mathrm{~V}$, adsorbed water is not available and the reaction can only proceed to adsorbed $\mathrm{CO}$ (indirect pathway) or formaldehyde (direct pathway). Dissociative methanol adsorption, exemplified in Eq. (6) with three available $\mathrm{Pt}$ sites $[12,40,41]$, is the rate-determining step. At intermediate potentials, 0.50-0.65 V, the Tafel slope indicates a mixed control where a large net change in $\mathrm{CO}$ coverage occurs. At high potentials, $0.65-0.80 \mathrm{~V}$, dissociative methanol oxidation, Eq. (6), is likely the rate-determining step as the CO coverage approaches zero. The calculated activation energies indicate a similar trend, with a rate-determinant dissociative adsorption step. The higher activation energies at low potentials, 0.50-0.65 V, support the interpretation from the Tafel slopes of a quickly changing (decreasing) CO coverage giving an additional enhancement. The dEIS data will help refine this interpretation and give more insight into the individual elementary reaction steps.

$$
3 \mathrm{Pt}+\mathrm{CH}_{3} \mathrm{OH} \rightarrow \mathrm{Pt}_{3} \mathrm{CH}_{2} \mathrm{OH}+\mathrm{H}^{+}+\mathrm{e}^{-}
$$

\subsection{Electrochemical impedance spectroscopy}

\section{Verification and EC fitting of experimental data}

Dynamic electrochemical impedance spectroscopy used within the boundaries established by Sacci et al. [21, 36] allows for measurement of reproducible impedance spectra while the electrochemical system is changing dynamically. An example of a cyclic voltammogram $\left(5 \mathrm{mV} \mathrm{s}^{-1}\right.$ at $100^{\circ} \mathrm{C}$ ) with representative impedance spectra at selected potentials is shown in Fig. 5. Up until $0.4 \mathrm{~V}$, the impedance spectra are all in the first quadrant best represented by the R' or R circuit in Fig. 1. After adsorbed water becomes available and until the peak current, 0.50 $0.80 \mathrm{~V}$, the low-frequency impedance goes into the fourth quadrant and an inductive loop becomes visible and can be successfully fitted by circuit L.

Based on this interpretation, the allowed equivalent circuits from Fig. 1 during the upward sweep are summarized below:

- $\mathrm{R}$ zone ( $\mathrm{R}$ or $\left.\mathrm{R}^{\prime}\right): 50$ - $400 \mathrm{mV}$

- L zone (R, R', or L): 400 - $800 \mathrm{mV}$

A useful test to see if all information is available in the measured frequency range, is to see if the low frequency intercept from the fitted data correspond with the slope of the cyclic voltammogram [21, 58]. This criteria is represented in Eq. (7). This analysis is shown in Fig. 6 where the derivative of the cyclic voltammogram was evaluated using a five point stencil in one dimension, $\mathrm{d} j / \mathrm{d} E \approx\left(j_{i-2}-8 j_{i-1}+8 j_{i+1}-j_{i+2}\right) / 12 h$, where $h$ is the potential step size and $j_{i \pm n}$ is the current density at $E_{i} \pm n h$.

$$
R_{\mathrm{p}}^{-1}=\operatorname{Re}(Z(\omega \rightarrow 0))^{-1} \approx \mathrm{d} j / \mathrm{d} E
$$

At higher temperatures (Fig. 6c-d) and during active CO oxidation $(E>450 \mathrm{mV})$, the fitted $R_{\mathrm{p}}^{-1}$ parameter gives approximately the same value as the derivative of the current potential curve. However, at $21^{\circ} \mathrm{C}$, Fig. 6a, the measured inverse resistance, $R_{\mathrm{p}}^{-1}$, was much smaller than the current derivative indicating that not all features are measured. The inductive loop observed at higher temperatures at these potentials is not observed at $21^{\circ} \mathrm{C}$. Therefore, it is assumed that the time constant for the inductive loop was too high (= characteristic frequency too low) for the frequency range used. To test this assumption, dEIS was measured at room temperature at a $0.5 \mathrm{mV} \mathrm{s}^{-1}$ sweep rate and a minimum frequency of 0.05 $\mathrm{Hz}$ (compared to $1 \mathrm{~Hz}$ at $5 \mathrm{mV} \mathrm{s}^{-1}$ ). The resulting $R_{\mathrm{p}}^{-1}$ values are shown in Fig. $6 \mathrm{~b}$. It is evident that the lower frequency limit manages to show all the features, and as expected, the additional feature is an inductive loop increasing the $R_{\mathrm{p}}^{-1}$ parameter. From this, it follows that care should be taken when interpreting data that fails the low-frequency intercept test as all information may not be available in the measured frequency range. Recently, a possible workaround has been proposed where a data point for the zero-frequency impedance is added based on the derivative of the cyclic voltammogram [59].

\section{EIS interpretation}

From the observed impedance spectra in Fig. 5, the semicircle with an inductive loop is the dominant spectrum between $0.5 \mathrm{~V}$ and $0.8 \mathrm{~V}$. This feature has been observed previously for both steady-state and dynamic electrochemical impedance measurements on methanol oxidation [23, 24, 27-29, 31-33]. This feature is firstly a clear indication that the mass transport limitations are negligible [30] and that there is no single rate-determining step so that the reactions producing and removing the adsorbate(s) proceed at similar rates [29, 60]. Furthermore, the inductive loop in the impedance spectra can be interpreted using a single-adsorbate mechanism [61]. From the simple model in Eqs. (1)-(3), it is evident that at least two species are present at the surface during methanol oxidation, i.e., $\mathrm{CO}$ and $\mathrm{OH}$. However, if one of these species dominate the overall reaction or if one of the adsorbates are in equilibrium with the solution, a complex mechanism involving several diffusing or adsorbing species can be reduced to a single-adsorbate mechanism. Notably, the calculated time constants of the influence of CO coverage from chronoamperometry correspond well with the experimental time constant $(\tau=L / R)$ of this feature and indicates that the inductive loop is due to the change in CO coverage. The reduced low-frequency resistance, $R_{\mathrm{p}}$, due to the inductive loop indicates that the change in $\mathrm{CO}$ coverage overall has a positive impact on the steady-state current. $\mathrm{CO}$ has been treated as the single adsorbate in the literature for the MOR [30], and based on such an interpretation, the impedance parameters from the $\mathrm{L}$ circuit can be related to kinetic parameters through Eqs. (8)-(11). 

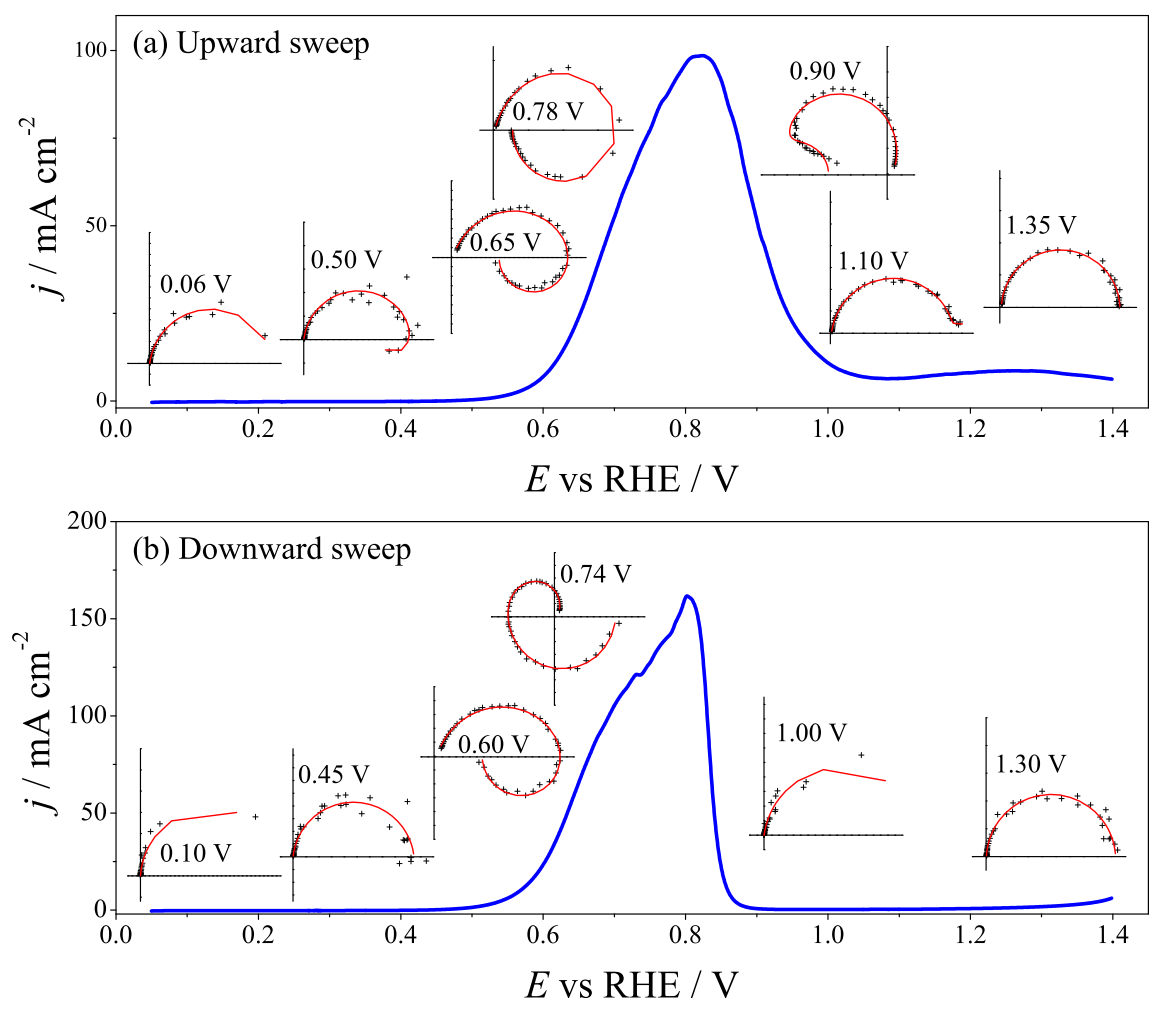

Figure 5: Figure showing the cyclic voltammogram at $100^{\circ} \mathrm{C}$ and $5 \mathrm{mV} \mathrm{s}^{-1}$ for the (a) upward sweep direction and (b) downward sweep direction. Insets show Nyquist representation of experimental impedance spectra (black crosses) with the equivalent circuit fit (red lines).
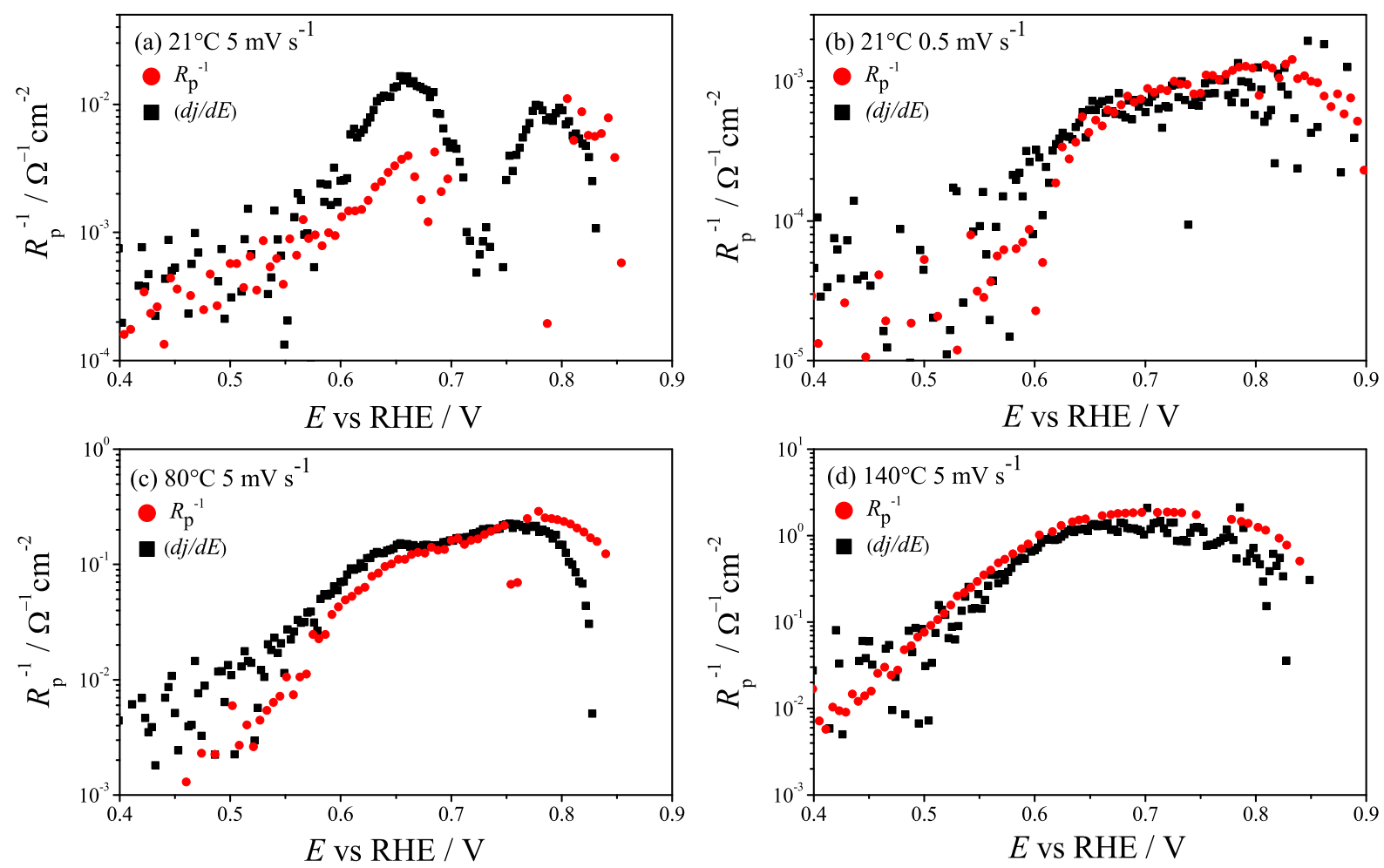

Figure 6: The fitted dEIS data showing the resolved dc path resistance, $R_{\mathrm{p}}^{-1}$ (red), and the derivative of the current, d $j / \mathrm{d} E$ (black), for the upward sweep direction at temperatures of (a) $21^{\circ} \mathrm{C}$ at $5 \mathrm{mV} \mathrm{s}^{-1}$ and (b) $21^{\circ} \mathrm{C}$ at $0.5 \mathrm{mV} \mathrm{s}^{-1}$, (c) $80^{\circ} \mathrm{C}$ at $5 \mathrm{mV} \mathrm{s} \mathrm{s}^{-1}$, and $(\mathrm{d}) 140^{\circ} \mathrm{C}$ at 5 $\mathrm{mV} \mathrm{s}^{-1}$. 

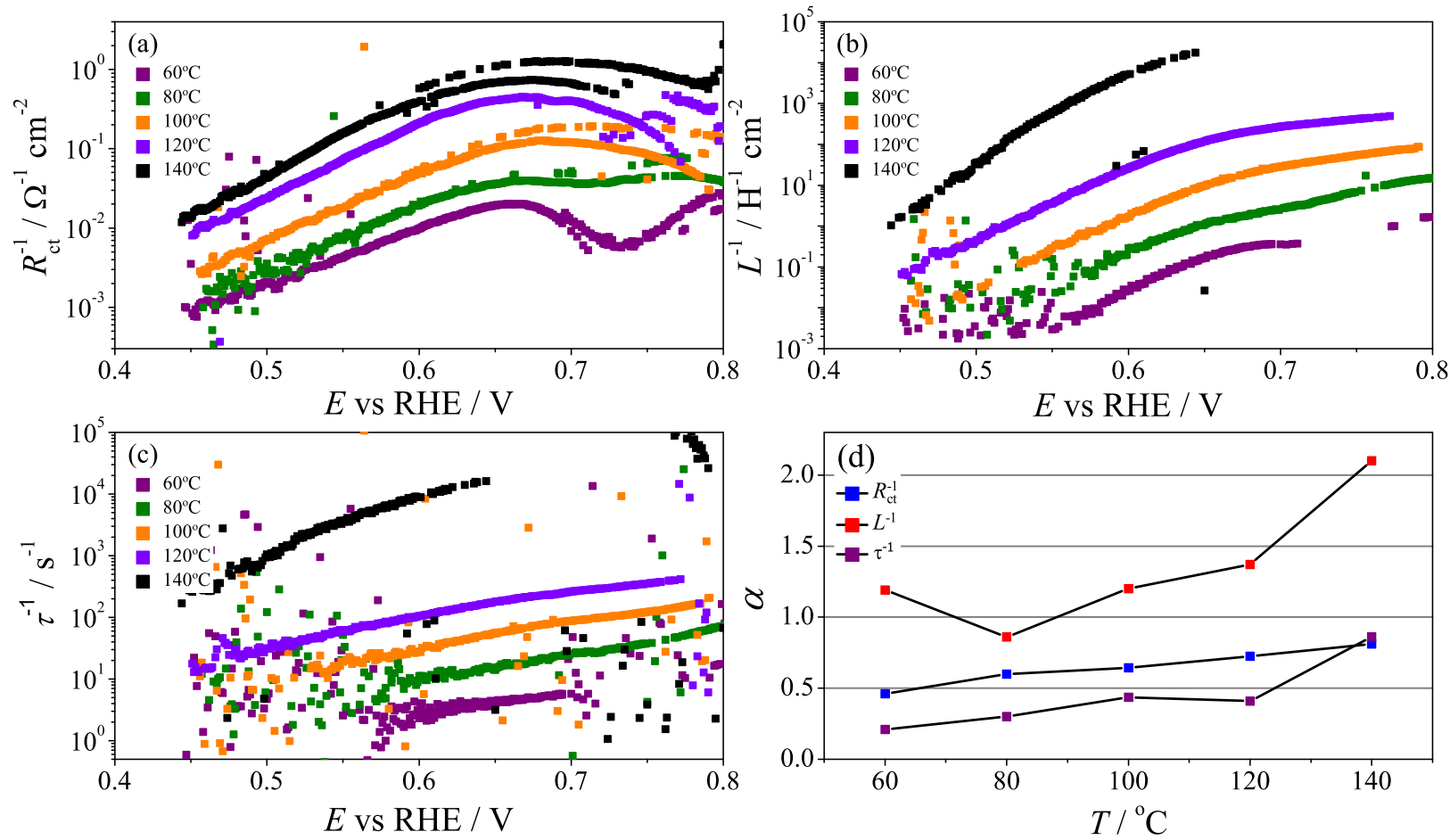

Figure 7: Fitted dynamic electrochemical impedance spectra data parameters (a) $R_{\mathrm{ct}}^{-1}$, (b) $L^{-1}$, and (c) $\tau^{-1}$ as a function of temperature and potential, and $(\mathrm{d})$ the calculated charge-transfer coefficients, $\alpha$, slopes based on the fitted parameters at potential below $0.65 \mathrm{~V}$.

$$
Y_{\mathrm{f}}=A+\frac{B}{\mathrm{i} \omega+C}
$$

Here, $Y_{\mathrm{f}}$ is the admittance, $\mathrm{i}$ is $\sqrt{-1}, \omega$ is the angular frequency, and $A, B$, and $C$ are potential-dependent parameters defined in Eqs. (9)-(11).

$$
\begin{gathered}
A=R_{\mathrm{ct}}^{-1}=F\left(\frac{\partial r_{\mathrm{e}}}{\partial E}\right)_{\theta} \\
B=L_{1}^{-1}=\frac{F}{\Gamma_{m}}\left(\frac{\partial r_{\mathrm{e}}}{\partial \theta}\right)_{E}\left(\frac{\partial r_{\mathrm{CO}}}{\partial E}\right)_{\theta} \\
C=R_{1} L_{1}^{-1}=\tau^{-1}=-\frac{1}{\Gamma_{m}}\left(\frac{\partial r_{\mathrm{CO}}}{\partial \theta}\right)_{E}
\end{gathered}
$$

Here, $r_{\mathrm{e}}$ is the rate of electron transfer (in $\mathrm{mol} \mathrm{cm} \mathrm{cm}^{-2}$ $\mathrm{s}^{-1}$ ), $\theta$ is the adsorbate coverage (between 0 and 1$), \Gamma_{m}$ is the surface concentration of Pt sites $\left(2.28 \times 10^{-9} \mathrm{~mol}\right.$ $\left.\mathrm{cm}^{-2}\right), \tau$ is the time constant of the inductive loop, $r_{\mathrm{CO}}$ is the rate of $\mathrm{CO}$ production, and $R_{\mathrm{ct}}, L_{1}$ and $R_{1}$ are impedance fitting parameters shown in Fig. 1 for the L circuit. The experimental impedance parameters from equivalent circuit fitting are presented in Fig. 7a-c for the temperatures that fulfilled the test in Fig. $6\left(\geq 60^{\circ} \mathrm{C}\right)$. Similar to the interpretation of the cyclic voltammogram, an apparent charge-transfer coefficient of each parameter can be calculated by fitting the slope to an exponential relation. These charge-transfer coefficients are presented in Fig. $7 \mathrm{~d}$ for potentials below $0.65 \mathrm{~V}$.

For the inverse charge-transfer resistance, $R_{\mathrm{ct}}^{-1}$ (Fig. $7 \mathrm{a})$, the slope is constant until the potential of the shoulder peak, and then is relatively steady (high temperatures) or drops quickly (low temperatures). The calculated chargetransfer coefficient at the lower potential increases with temperature and ranges between 0.46 (at $21^{\circ} \mathrm{C}$ ) and 0.81 (at $140^{\circ} \mathrm{C}$ ). The derivative in Eq. (9) can not be quantified unless a complete reaction mechanism is suggested. However, this trend is qualitatively similar to the overall Tafel slope in Fig. 2d, with a change of slope at the potential of the shoulder peak $(0.60-0.65 \mathrm{~V})$.

The inverse inductance, $L^{-1}(7 \mathrm{~b})$, has a constant slope until the shoulder peak similar to the charge-transfer resistance. For example, at $120^{\circ} \mathrm{C}$, the inverse time constant is about $40 \mathrm{~s}^{-1}$ at $0.55 \mathrm{~V}$ giving a time-constant of $0.025 \mathrm{~s}$ corresponding well with the $0.05 \mathrm{~s}$ observed from chronoamperometry data. The complex relation influencing this parameter according to Eq. (10) makes only a qualitative interpretation possible within the scope of this work. As the inductive loop is likely related to the relaxation due to the change in CO coverage, the actual value of the inductor is also related to this value. If a reversible $\mathrm{OH}$ adsorption is assumed, the surface reaction between adsorbed $\mathrm{CO}$ and $\mathrm{OH}$ will control this rate. Depending on the nature of this reaction, either chemical or electrochemical, a charge-transfer coefficient of about 1-1.5 can be expected.

The inverse time constant, $\tau^{-1}$ (Fig. 7c), corresponds well with the time constants found from the chronoamperometry data due to change in $\mathrm{CO}$ coverage. The parameter has a relatively constant slope as a function of potential and a change at the shoulder peak potential is not visi- 
ble. From Eq. (11), this can be interpreted as the partial derivative of the net adsorbate production, $r_{\mathrm{CO}}$, with respect to the coverage, $\theta_{\mathrm{CO}}$, at a constant potential. As the $r_{\mathrm{CO}}$ parameter is dependent on $\mathrm{CO}$ production (Eq. (1)) and CO oxidation step (Eq. (3)), the change due to coverage can be expected to be larger for the $\mathrm{CO}$ production step, especially if it is dependent on more than one available site as in Eq. (6).

Although the dEIS data is only qualitatively analysed here, the inductive loop may reliably be assigned to changing $\mathrm{CO}$ coverage, as previously suggested [61]. In the range where the CO coverage changes quickly $(0.55-0.65 \mathrm{~V})$, this has a large net positive effect resulting in a lower overall low-frequency impedance, $R_{\mathrm{p}}$, and in higher currents. These observations are in accordance with the conclusions from the steady-state techniques and further support these conclusions.

\subsection{The reaction mechanism of the MOR}

From the experimental data reported in this work, a detailed reaction mechanism for the MOR can be proposed. Expanding on the notion that the reaction proceeds via dual pathways, and the literature observations summarized in points 1-5 in Section 3.1, a suggested reaction mechanism for the indirect pathway is given in Eqs. (12)(16). A chemical surface reaction, Eq. (15) is included here as it gives better optimization results when fitted to experimental data in the literature [15, 29].

$$
\begin{gathered}
3 \mathrm{Pt}+\mathrm{CH}_{3} \mathrm{OH} \rightarrow \mathrm{Pt}_{3} \mathrm{CH}_{2} \mathrm{OH}+\mathrm{H}^{+}+\mathrm{e}^{-} \\
\mathrm{Pt}_{3} \mathrm{CH}_{2} \mathrm{OH} \rightarrow \mathrm{PtCO}+2 \mathrm{Pt}+3 \mathrm{H}^{+}+3 \mathrm{e}^{-} \\
\mathrm{Pt}+\mathrm{H}_{2} \mathrm{O} \rightleftarrows \mathrm{PtOH}+\mathrm{H}^{+}+\mathrm{e}^{-} \\
\mathrm{PtCO}+\mathrm{PtOH} \rightarrow \mathrm{PtCOOH}+\mathrm{Pt} \\
\mathrm{PtCOOH} \rightarrow \mathrm{CO}_{2}+\mathrm{Pt}+\mathrm{H}^{+}+\mathrm{e}^{-}
\end{gathered}
$$

In addition, the direct pathway can proceed in parallel with the indirect pathway and produce formaldehyde at all potentials, and formic acid and $\mathrm{CO}_{2}$ where adsorbed water is available $(E>0.50 \mathrm{~V})$.

In the fuel cell relevant range, $0-0.8 \mathrm{~V}$, the rate-determining step and reaction mechanism changes several times as different reaction steps are activated. At low overpotentials, $<0.50 \mathrm{~V}$, the water adsorption reaction, Eq. (14), is not active and only formaldehyde and adsorbed CO can be produced from methanol oxidation. The rate-determining step in the indirect pathway is adsorption of methanol. The CO coverage builds up until it reaches a maximum coverage [12] either due to the site demand or repulsive interaction between the adsorbates.

As the water adsorption reaction is activated, $\mathrm{CO}$ can be removed through its reaction with $\mathrm{OH}$. The removal is relatively slow and partly determines the rate. There is mixed control in the region until the shoulder peak at 0.60-0.65 V, with both the CO-producing step, methanol adsorption, and the CO-removal step, the surface reaction between $\mathrm{CO}$ and $\mathrm{OH}$, influencing the rate. This is the case until the shoulder peak at $0.60-0.65 \mathrm{~V}$.

At the shoulder peak, the CO coverage approaches zero and then the rate is no longer influence by the removal of CO. This leads to a drop in charge-transfer coefficient with the rate again solely determined by the methanol adsorption step.

The adsorbed methanol can oxidize either through adsorbed $\mathrm{CO}$ or the direct pathway. This is also consistent with the trend in selectivity reported in the literature, where the highest $\mathrm{CO}_{2}$ selectivity is obtained at potentials where $\mathrm{CO}$ coverage is significant and decreases with increasing potential [6]. Thus, when the adsorbed CO has been removed, the indirect and direct pathways compete, and the selectivity is determined by the relative rate of these pathways when oxidizing the adsorbed methanol.

While the MOR is qualitatively well-described by the reaction mechanisms given in Eqs. (12)-(16), many details remain to be understood. For example the nature of the surface reaction between adsorbed $\mathrm{CO}$ and $\mathrm{OH}$, the number of $\mathrm{Pt}$ sites necessary for (dissociative) methanol adsorption, and the role and relative rates of the different reaction pathways. Currently, we are developing an optimization procedure that can optimize kinetic parameters in a given reaction mechanism by fitting to cyclic voltammograms [62]. The deduced kinetic parameters can subsequently be used to calculate the dEIS spectra at fixed potentials and discriminate between similar reaction mechanisms.

\section{Conclusions}

Cyclic voltammetry and chronoamperometry were conducted for the MOR on platinum at temperatures from $21^{\circ} \mathrm{C}$ and $140^{\circ} \mathrm{C}$. Dynamic electrochemical impedance spectroscopy combined with cyclic voltammetry allows for online monitoring of the surface state during cyclic voltammetry. A mechanistic analysis based on the Tafel behavior, calculated activation energies, and equivalent circuit fitting of the dEIS spectra and literature data showed that:

1. The MOR is hindered by the availability of adsorbed water at low overpotentials, $<0.50 \mathrm{~V}$. A net increase in $\mathrm{CO}$ coverage until saturation coverage and low total current is the result.

2. Adsorbed water becomes available above about 0.50 $\mathrm{V}$. The overall current is controlled by both the methanol adsorption reaction and the surface reaction between adsorbed intermediates. An increase in potential leads to net removal of $\mathrm{CO}$.

3. The inductive loop in the dEIS spectra is due to the change in $\mathrm{CO}$ coverage, and that this change has a net positive effect on the current.

4. The shoulder peak at $0.60-0.65 \mathrm{~V}$ corresponds to decrease of the CO coverage to low values. The ratedetermining step is methanol adsorption past this potential. 


\section{Acknowledgment}

This work was financially supported by the Natural Sciences and Engineering Research Council of Canada through its Discovery Frontiers program (Engineered Nickel Catalysts for Electrochemical Clean Energy project administered from Queen's University, grant RGPNM 4779632015) and Discovery Grants program (grant 37035), and by the Research Council of Norway through projects 178478 and 221899 as well as the INTPART project 261620. P.K.D. and T.H. thank the Department of Materials Science and Engineering at NTNU for individual Scholarships. T.H. thanks Andreas Holm for the help with efficient data processing.

[1] S. Wasmus, A. Küver, Journal of Electroanalytical Chemistry 461 (1999) 14-31.

[2] J. L. Cohen, D. J. Volpe, H. D. Abruna, Phys. Chem. Chem. Phys. 9 (2007) 49-77.

[3] H. Liu, C. Song, L. Zhang, J. Zhang, H. Wang, D. P. Wilkinson, Journal of Power Sources 155 (2006) 95-110.

[4] S. Sharma, B. G. Pollet, Journal of Power Sources 208 (2012) 96-119.

[5] T. Iwasita, Electrochimica Acta 47 (2002) 3663-3674.

[6] M. Chojak-Halseid, Z. Jusys, R. J. Behm, The Journal of Physical Chemistry C 114 (2010) 22573-22581.

[7] M. Heinen, Y.-X. Chen, Z. Jusys, R. J. Behm, ChemPhysChem 8 (2007) 2484-2489.

[8] M. Heinen, Y. X. Chen, Z. Jusys, R. J. Behm, Electrochimica Acta 53 (2007) 1279-1289.

[9] Y. Chen, A. Miki, S. Ye, H. Sakai, M. Osawa, Journal of the American Chemical Society 125 (2003) 3680-3681.

[10] T. Yajima, H. Uchida, M. Watanabe, Journal of Physical Chemistry B 108 (2004) 2654.

[11] K. Kunimatsu, H. Hanawa, H. Uchida, M. Watanabe, Journal of Electroanalytical Chemistry 632 (2009) 1090-119.

[12] H. A. Gasteiger, N. Marković, P. N. Ross, E. J. Cairns, Journal of The Electrochemical Society 141 (1994) 1795-1803.

[13] F. W. Hartl, A. A. Zülke, B. J. Fonte, H. Varela, Journal of Electroanalytical Chemistry 800 (2017) 99-105.

[14] G. B. Melle, F. W. Hartl, H. Varela, E. Sitta, Journal of Electroanalytical Chemistry 826 (2018) 164-169.

[15] P. S. Kauranen, E. Skou, J. Munk, Journal of Electroanalytical Chemistry 404 (1996) 1-13.

[16] T. Vidakovic, M. Christov, K. Sundmacher, Journal of Electroanalytical Chemistry 580 (2005) 105-121.

[17] D. A. Harrington, Journal of Electroanalytical Chemistry 355 (1993) 21-35.

[18] M. E. van der Geest, N. J. Dangerfield, D. A. Harrington, Journal of Electroanalytical Chemistry 420 (1997) 89-100.

[19] F. Seland, R. Tunold, D. A. Harrington, Electrochimica Acta 53 (2008) 6851-6864.

[20] G. Ragoisha, N. P. Osipovich, A. S. Bondarenko, J. Zhang, S. Kocha, A. Iiyama, Journal of Solid State Electrochemistry 14 (2010) 531-542.

[21] R. Sacci, F. Seland, D. Harrington, Electrochimica Acta 131 (2014) 13-19.

[22] G. Ragoisha, Electroanalysis 27 (2015) 855-863.

[23] W. Tokarz, P. Piela, A. Czerwinski, Journal of Solid State Electrochemistry 14 (2010) 515-521.

[24] D. C. Azevedo, W. H. Lizcano-Valbuena, E. R. Gonzales, Journal of New Materials for Electrochemical Systems 7 (2004) 191196.

[25] F. Seland, R. Tunold, D. A. Harrington, Electrochimica Acta 51 (2006) 3827-3840.

[26] F. Seland, R. Tunold, D. A. Harrington, Electrochimica Acta 55 (2010) 3384-3391.

[27] C. Désilets, A. Lasia, Electrochimica Acta 78 (2012) 286-293.
[28] P. K. Dahlstrøm, D. A. Harrington, F. Seland, ECS Transactions 41 (2012) 35-47.

[29] U. Krewer, M. Christov, T. Vidakovic, K. Sundmacher, Journal of Electroanalytical Chemistry 589 (2006) 148-159.

[30] J. T. Muller, P. M. Urban, W. F. Holderich, Journal of Power Sources 84 (1999) 157-160.

[31] N.-Y. Hsu, S.-C. Yen, K.-T. Jeng, C.-C. Chien, Journal of Power Sources 161 (2006) 232-239.

[32] R. E. Melnick, G. T. R. Palmore, Journal of Physical Chemistry B (2001).

[33] D. Chakraborty, I. Chorkendorff, T. Johannessen, Journal of Power Sources 162 (2006) 1010-1022.

[34] T. Holm, P. K. Dahlstrøm, S. Sunde, D. A. Harrington, F. Seland, ECS Transactions 75 (2016) 1055-1061.

[35] T. Holm, P. K. Dahlstrøm, O. S. Burheim, S. Sunde, D. A. Harrington, F. Seland, Electrochimica Acta 222 (2016) 17921799.

[36] R. Sacci, D. Harrington, ECS Transactions 19 (2009) 31-42.

[37] G. S. Popkirov, R. N. Schindler, Review of Scientific Instruments 64 (1993) 3111-3115.

[38] B. Beden, F. Hahn, S. Juanto, C. Lamy, J.-M. Leger, Journal of Electroanalytical Chemistry and Interfacial Electrochemistry 225 (1987) 215-225.

[39] S. Liu, L. Liao, Q. Tao, Y. Chen, S. Ye, Phys. Chem. Chem. Phys. 13 (2011) 9725-9735.

[40] A. Cuesta, Journal of the American Chemical Society 128 (2006) 13332-13333.

[41] M. Neurock, M. Janik, A. Wieckowski, Faraday Discuss. 140 (2009) 363-378

[42] J. Rossmeisl, J. Nørskov, C. Taylor, M. Janik, M. Neurock, Journal of Physical Chemistry B 110 (2006) 21833-21839.

[43] J. Rossmeisl, P. Ferrin, G. A. Tritsaris, A. U. Nilekar, S. Koh, S. E. Bae, S. R. Brankovic, P. Strasser, M. Mavrikakis, Energy Environ. Sci. 5 (2012) 8335-8342.

[44] A. Cuesta, Current Opinion in Electrochemistry 4 (2017) 32-38.

[45] W. Chen, J. Cai, J. Yang, M. M. Sartin, Y.-X. Chen, Journal of Electroanalytical Chemistry 800 (2017) 89-98.

[46] A. B. Anderson, T. Albu, Journal of The Electrochemical Society 147 (2000) 4229-4238.

[47] A. B. Anderson, N. Neshev, R. Sidik, P. Shiller, Electrochimica Acta 47 (2002) 2999-3008.

[48] V. Viswanathan, H. Hansen, J. Rossmeisl, T. Jaramillo, H. Pitsch, J. Nørskov, The Journal of Physical Chemistry C 116 (2012) 4698-4704.

[49] J. O'M Bockris, Z. Nagy, Journal of Chemical Education 50 (1973) 839-843.

[50] S. L. Gojkovic, T. R. Vidakovic, Electrochimica Acta 47 (2001) 633-642.

[51] G. Hou, J. Parrondo, V. Ramani, J. Prakash, Journal of The Electrochemical Society 161 (2014) F252-F258.

[52] E. Mostafa, A. A. Abe-El-Latif, H. Baltruschat, Chemical Physics Physical Chemistry 15 (2014) 2029-2043.

[53] A. Sayadi, P. G. Pickup, Electrochimica Acta 199 (2016) 12-17.

[54] M. Heinen, Y. X. Chen, Z. Jusys, R. J. Behm, Electrochimica Acta 52 (2007) 5634-5643.

[55] Y.-H. Fang, Z.-P. Liu, ACS Catalysis 4 (2014) 4364-4376.

[56] Y.-H. Fang, Z.-P. Liu, Surface Science 631 (2015) 42-47.

[57] E. Gileadi, Journal of Solid State Electrochemistry 15 (2011) 1359-1371.

[58] D. A. Harrington, P. van den Driessche, Electrochimica Acta 56 (2011) 8005-8013.

[59] M. A. A. Kappel, R. Fabbri, R. P. Domingos, I. N. Bastos, Measurements 94 (2016) 344-354.

[60] D. A. Harrington, Journal of Electroanalysical Chemistry 737 (2015) 30-36.

[61] D. A. Harrington, B. E. Conway, Electrochimica Acta 32 (1987) 1703-1712.

[62] T. Holm, D. A. Harrington, ECS Transactions 85 (2018) 167176. 